\title{
BIM 技术在高速公路桥梁施工安全管理中的应用
}

\author{
柴广
}

贵州路桥集团有限公司，贵州 贵阳 550000

[摘要] 当前时期, 国内经济呈现出较快的发展态势, 在此背景下, 高速公路建设逐渐加快, 这就为不同区域间的往来奠定了 基础。展开高速公路桥梁施工时必须要保证相关环节能够形成紧密的关联性, 而要保证施工安全, 就必须要将安全管理予以 有效落实。将 BIM 技术予以应用可以对施工的整个过程进行模拟, 这样就能够将潜在隐患寻找出来, 在施工时就可予以消除, 整个施工效率能够有大幅提升。文章主要针对高速公路桥梁施工中如何展开施工安全管理进行深入探析, 重点阐述 BIM 技术 的应用策略，针对其中存在的问题提出切实可行的解决之策。

[关键词]高速公路; 桥梁施工; 安全管理; BIM 技术; 应用

DOI：10.33142/sca.v3i5.2292 中图分类号：U415.12;U445.1 文献标识码: A

\section{Application of BIM Technology in Safety Management of Highway Bridge Construction \\ CHAI Guang \\ Guizhou Road \& Bridge Group Co., Ltd., Guiyang, Guizhou, 550000, China}

\begin{abstract}
In the current period, the domestic economy shows a rapid development trend. Under this background, the construction of expressway is gradually accelerated, which lays the foundation for the exchanges between different regions. In the construction of expressway bridge, it is necessary to ensure that the relevant links can form a close correlation, and to ensure the construction safety, it is necessary to effectively implement the safety management. The application of BIM Technology can simulate the whole process of construction, so that the potential hidden dangers can be found out and eliminated during construction, and the whole construction efficiency can be greatly improved. This paper mainly discusses how to carry out construction safety management in highway bridge construction, focuses on the application strategy of BIM Technology, and puts forward feasible solutions to the existing problems.
\end{abstract}

Keywords: expressway; bridge construction; safety management; BIM technology; application

引言

在我们国家, 高速公路建设工作正在稳步推进, 施工企业所要面对的竞争压力也持续增加, 对于企业而言, 若想 保持竞争优势的话, 就必须要认识到安全管理的重要性, 将 BIM 技术予以充分应用, 构建起完善的管理模型, 通过其 就可使得施工管理工作有序展开，而且管理的实效性也能够得到切实保证。

\section{BIM 的含义}

所谓BIM, 即是对三维数字技术的作用切实发挥出来, 建立起建筑信息模型, 并将相关的数据汇总起来, 构建起完 整的数据库。通过 BIM 模型能够将工程项目的功能清晰呈现出来, 这样就能够对工程建设的实际情况有切实的了解。 现阶段, 很多的工程项目中已经对 BIM 技术予以应用, 并取得了理想的效果。从高速公路桥梁施工来说, 在展开施工 安全管理时, BIM 技术的应用能够使得管理效果更为理想。

\section{BIM 技术在高速公路桥梁施工安全管理中的价值}

BIM 技术是以三维数字技术为基础, 建立起完善的建筑信息模型, 同时完成数据收集、存储, 获得完成的数据库。 对数字化技术予以应用, 这样就能够对施工进行模拟, 并将施工中存在的问题寻找出来, 如此就可保证施工有序展开。 在展开高速公路桥梁施工时, 安全管理是不可忽视的, 通过 BIM 技术可以完成好静态模型的构建工作, 主体结构、设 施建设、施工情况等均可在其中展现出来; 以时间维度为基础, 依据工程进度可以构建起动态模型, 这样就可对施工 作业的实际情况进行模拟分析。从整个工程管理中, 施工安全管理是十分重要的组成部分, 施工的所有环节均纳入到 管理范围中, 可以对施工目标的达成起到促进作用。和传统安全管理予以比较可知, 通过 BIM 技术展开安全管理可以 使得工程统筹规划切实完成, 安全管理的实效性有大幅提升, 而且可以保证施工的安全。将 BIM 技术的作用切实发挥 出来，可以对信息资料进行收集、分析，并对施工的整体状况予以监控，这样就可使得相关的管理工作更具实效性， 
施工安全也能够得到保证。[2]

\section{BIM 整体框架}

\section{1 BIM 主要面向对象}

在 BIM 模型中包含大量的信息, 利用这些信息就能够建立起各种安全管理系统, 比方说 3D 电子施工日志、可视化 成果、桥梁信息管理等, 在展开高速公路桥梁施工时, 这些均是十分重要的。BIM 技术应用框架见图 1, 对网络予以有 效利用就可使得数据传递、数据共享等目标切实达成。

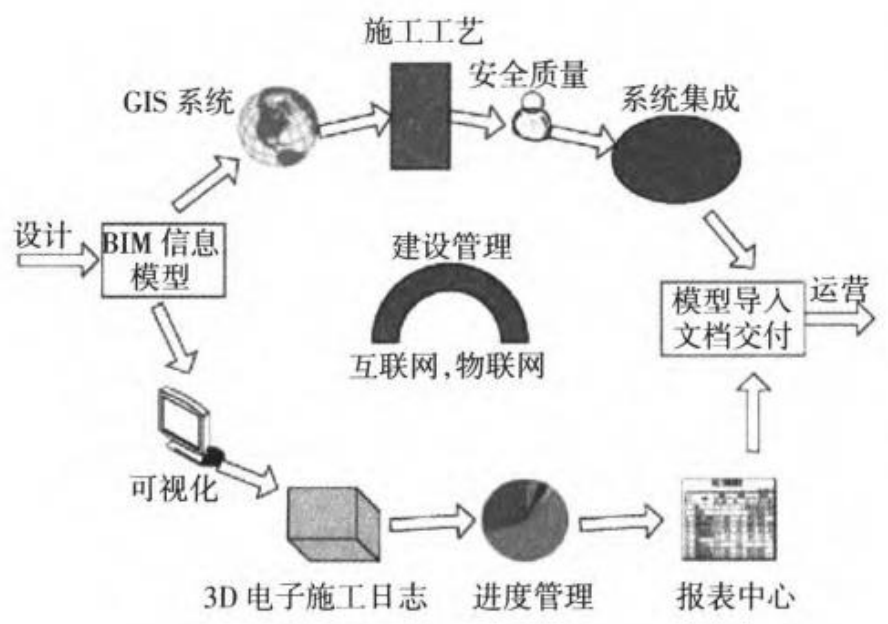

\section{2 框架介绍}

图 1 BIM 主要面向对象

对 BIM 框架予以分析可知, 其组成部分共有两个, 即信息安全集成管理系统、BIM 模型, 采用的技术则分别是 B/S 技术、 $\mathrm{C} / \mathrm{S}$ 技术, 通过接口使得两者能够切实连接起来, 这样一来, 安全信息就能够真正实现共享, 而且沟通效率也会 得到切实提升。在互联网技术中, $\mathrm{B} / \mathrm{S}$ 技术、 $\mathrm{C} / \mathrm{S}$ 技术的应用是较为常见的, 其是将互联网服务器、汶览器予以整合的 技术，对这两种技术充分利用的话，能够使得数据集成、共享能够实现，同时可以对相关数据进行加工、传递。 ${ }^{[3]}$

\section{4 高速公路桥梁施工安全管理中 BIM 技术应用途径}

\section{1 施工风险感知管理理论}

在展开高速公路施工时, 桩基检测、路基开挖以及边坡巩固等均属于隐蔽工程, 安全管理工作要切实予以加强。 边坡施工是不能忽视的, 为了保证其更为稳定, 必须要将加固处理做到位, 如此方可使得通车安全得到保证。构建高 速公路 BIM 模型时, 应该要对构件信息予以重视, 确保信息转换目标能够切实达成, 并依据实际需要做好相关的调整 工作。从高速公路施工的实际情况来看, 通过 BIM 数据库可以将每个构件的情况清晰呈现出来, 不同施工阶段可以获 得所需的信息, 而且这些信息是非常精准的。由安全信息角度来说, 进行高速公路施工的过程中要依据每个阶段的实 际需要来将安全标准、质量标准予以明确, 进而完成好检查工作。在对施工风险控制模板予以实际应用时, 必须要完 成好风险识别工作, 并提出切实可行的防范之策, 在此基础上构建起行之有效的预警机制。展开 BIM 项目综合管理时, 要对决策分析予以重视, 相关的管理工作应该加强, 并确保进度、安全、质量等能够保持平衡关系, 也就是要保证施 工质量达到要求, 安全性大幅提高, 并使得项目施工能够如期完成。

\section{2 加强施工空间管理}

在展开高速公路桥梁施工时, 整个施工过程显得较为复杂, 产生影响的因素是较多的, 如果没有控制到位的话, 施工的质量、安全就难以保证。对施工空间进行管理时, 要依据工程项目的现状完成好决策设计、合同管理, 将 BIM 技术予以充分利用就可使得管理有效性大幅提高。进行项目设计时, 通过 BIM 技术能够对相关的数据予以收集, 并加 以分析, 确保施工方案能够和工程现状相吻合, 整个施工过程能够更为安全。对 BIM 技术予以应用能够对施工现场进 行模拟, 切实完成好现场监测工作, 如果发现问题的话, 则可展开综合分析, 如此一来, 安全风险管理的实效性就能 够提高很多。 ${ }^{[4]}$ 


\section{3 安全疏散模型的建立}

对安全疏散模型进行分析可知, 其基本架构涵盖的内容是较多的, 疏散主体、场所、空间等均在其中。通过其能 够对疏散的人员、速度、通道、面积、材料等予以模拟, 尤其是在进行人员疏散时, 可以将拥挤程度、人员位置等呈 现出来, 保证安全疏散工作能够有序展开。另外来说, BIM 模型在可视性方面是具有明显优势的, 通过其可以对每个施 工阶段进行模拟, 通过动态方式将现场实际情况予以呈现, 这样在展开现场管理时就能够获得有效的指导。在对安全 疏散模型进行构建的过程中, 疏散主体、环境是不能忽视的, 尤其是要对人员心理以及主观动态予以重点关注, 如此 可以将真实情况模拟出来。对仿真模型进行构建时, 要对各种影响因素进行考虑, 如此方可使得项目管理的实效性大 幅提高。

\section{4 施工中的数据监测与优先级事故处理}

展开高速公路施工时, BIM 技术人员必须要对查询模板进行适当优化, 这样方可保证项目部对施工情况有切实了解, 使得预警保障机制具有的实时性能够大幅提升, 针对施工中可能出现的安全事故予以划分, 明确事故等级, 进而做好 跟踪监测。有些安全事故产生的影响是非常严重的, 比方说在对边坡进行开挖时发生了塌方、滑落等，一旦出现此类 事故则要在第一时间上报。对施工过程中发生的事故应该要进行统计、分析, 并通过可行的措施来对安全隐患予以排 除。针对施工安全进行管控的过程中, 最为关键的是风险预防, 要寻找到切实可行的防范措施, 通过 BIM 建筑信息模 型来对结构安全展开深入分析, 在获得实时监测数据后就能够对动态结构具有的安全性进行预测, 并针对危险区域展 开分级处理。技术人员必须要针对每道施工工序展开细致检查, 了解其和既定的安全标准是否相符, 尤其是要针对空 间冲突予以检查。从安全管理的实际情况来看, 要从安全分类出发, 将冲突类别予以明确, 进而就可针对优先级展开 处理。对于技术人员而言, 要对进度管理予以重视, 切实完成好信息资源的收集与整理, 施工中使用的材料、机械必 须要保证能够满足实际需要，如此方可使得后续的施工获得资料支持，施工安全可以得到切实保证。[

\section{5 施工安全管理}

展开施工安全管理时, 要将 BIM 技术的作用充分发挥出来, 利用虚拟建造技术可以获得直观的模型, 通过其就可 将施工的整个过程清晰呈现。管理人员在正式施工前就可对虚拟模型进行观察，从而了解施工的每个细节，针对质量、 安全等方面存在的问题展开全面分析, 并选择可行的措施予以防范, 这样就可在虚拟环境中完成施工管理。另外来说, 在展开高速公路施工时，进度管理也是不可忽视的，对施工进度产生影响的因素是较多的，施工技术、周边环境以及 施工方案等均会带来一定程度的影响, 如果实际进度、计划进度间存在明显偏差的话, 工程质量就难以得到保证, 而 且施工单位、业主间发生冲突的概率会大幅增加。当然, 如果将关注点完全放在施工进度方面的话, 那么施工安全就 很难得到保证。高速公路施工时要对 BIM 技术予以有效利用, 通过 4D 模拟就能够对施工的界面、顺序、结果、质量等 清晰呈现出来, 总包方、分包方能够对施工工序有切实的了解, 并可使得施工组织、安全管理能够切实整合起来, 这 样就能够提高施工管理的实效性。从现代企业的角度来说，BIM 技术的应用是较为普遍的，通过其能够对施工进度展开 有效的管控，施工能够有序展开，安全隐患可以得到切实消除，整个工程项目的建设可以顺利完成。 ${ }^{[6]}$

\section{5 结语}

由上可知, 在展开高速公路桥梁施工的过程中, 安全管理是不可忽视的, 将 BIM 技术予以充分应用可以使得管理 效果更为理想。从事管理工作的相关人员必须要将安全规划切实做到位, 并构建起安全隐患识别体系, 将安全管理落 实到施工的整个过程中。在项目运行阶段中要将维护、消防等方面的管理予以加强, 尤其要对使用质量安全作为重点 关注对象，将既定的管理标准予以有效落实，这样方可使得管理效率有大幅提升，工程项目的安全性得到切实保证。

\section{[参考文献]}

[1]金文晶,杨彪. BIM 技术在高速公路桥梁施工安全管理中的应用 [J].科技经济导刊, 2020,28(17): 22 .

[2]王伟,李国峰. BIM 技术在高速公路桥梁施工安全管理中的应用 [J]. 公路, 2020,65(06): 176-178.

[3] 装威. 分析 BIM 技术在高速公路桥梁施工安全管理中的应用 [J]. 居舍, 2020 (01) : 66.

[4]王念隆. BIM 技术在高速公路施工安全管理中的应用 [J].交通世界,2019(14) : 133-134.

[5]马保林. 分析 BIM 技术在高速公路桥梁施工安全管理中的应用 [J]. 工程建设与设计, 2019 (04) : 226-227.

[6]刘宏剑. BIM 技术在高速公路施工安全管理中的应用 [J]. 城市建设理论研究 (电子版), 2017 (07) : 175-176.

作者简介：柴广（1991-)，贵州交通职业技术学院，道路与桥梁工程，工程师。 